\title{
JUURNAL.RU
}

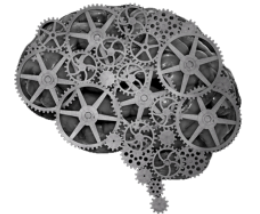

COMPANY GROUP "INTELLEKT"

\author{
Митрофанова Ю.А. \\ ФГ БОУ ВПО «Государственный университет управления» \\ Москва, Россия
}

doi: 10.18411/1j2016-5-2-18

\section{Аспекты формирования учетно-аналитической системы финансовых результатов}

\section{Аннотация:}

Известно, что целью каждой организации является получение максимальной прибыли. Для достижения этой цели важнейшими признаки являются, финансовая устойчивость. Узнать информацию о финансовохозяйственной деятельности, предприятиям помогает учетно-аналитическая система, которая т помогает принять решения для устранения недостатков управленческой деятельности. Состав этой системы состоит из бухгалтерского учета, бюджетирования, управленческой отчетности и анализа.

\section{Ключевые слова:}

Учетно-аналитическая система, формирование, управление, финансовый результат

Учетно-аналитическая система необходима для того, чтобы соединить воедино финансовые показателии на основании этого анализировать, в дальнейшем прогнозировать и устранять отклонения выявленных погрешностей.

Для начала было бы важно упомянуть о том, что включает в себя учетноаналитическая система. На данных бухгалтерского учета, строятся все дальнейшие анализы учетно-аналитической системы, т.к. он отражает в первую очередь движение денежных средств. В бухгалтерской отчетности отражается вся деятельность предприятия, которая является достоверной, и которая может 
дать объективное представление о предприятии. Бюджетирование, это один из процессов, который включает в себя разработки планов для эффективного функционирования и контроля поставленных целей, дает понять, где происходили отклонение от этого плана, и помогает скорректировать их для улучшения показателей. Управленческая отчётность в свою очередь позволяет выделить определенные проблемы управленческого характера, чтобы для дальнейшего их устранить в зависимости от потребностей. Управленческий анализ представляет собой оценку на основании аналитических данных при промежуточной обработке, от его эффективности зависит результат деятельности, что является основной целью.

Впервые о формировании учетно-аналитических систем в России, рассказали в своей работе И.П. Ульянов и Л.В. Попова в 90-х. По их мнению, формирование учетно-аналитической системы - это создание сквозной экономической системы посредством соответствующего справочноинформационного фонда на основе баз данных, используемого для формирования системы аналитических показателей- инструментов выработки оперативных, тактических и стратегических управленческих решений.

По мнению Л.В. Усатовой комплекс процессов непрерывного сбора, обработки и оценки информации и есть понимание учетно-аналитической системы. Одними из важных элементов, которые составляют основу интернациональной модели учетно-аналитической системы, являются международные стандарты, которые носят рекомендательный характер и имеют все большее значение.

Важным вопросом является, как ввести учётно-аналитическую систему на предприятие, чтобы она, верно, функционировала и помогала достичь поставленных целей за счет выявление ошибок с последующей их ликвидацией.Также, данная система, должна помогать лицам,работающим с финансами и контролируемым данную систему, давать ответы на важные для 
них вопросы, чтобы разрабатывать все новые формы для облегчения каких либо задач.

Еще одним из важных вопросов является то, как необходимо разбить затраты по подразделениям, но также не упустить их из виду при дальнейшем планировании на следующие периоды. Сколько задействовано ресурсов на осуществление продаж или предоставление услуг.

Когда говорят о транспорте, то надо задуматься что в этой отросли, есть много особенностей связанных с построением верной учетно-аналитической системы, которая будет работать. Например, управленческая учетноаналитическая система транспортной отросли, должна в первую очередь верно установить планирование затрат на предприятии, что является главным, а что дополнительными затратами непосредственно связанных с перевозками. Важно установить затраты которые непосредственно связаны с деятельностью организации.

Одним из важных фактором при перевозке является построение пути, в настоящие время при появление платных дорог, при этом возникает вопрос что это либо затраты непосредственно связанные с реализацией , либо это издержки предприятия, выраженные ка к дополнительные затраты. Требуется ли перевозка через заграницу, что уже будет включать в себя таможенную пошлину. Также потребуются ли погрузо-разгрузочные работы, что уже будет вступать как либо дополнительная услуга, либо предоставляется непосредственно как основная.

С задачами, связанными с построением управленческо-аналитической системы руководители предприятий в любых отраслях, возникла необходимость усовершенствовать внутреннюю систему управления, которая помогла бы контролировать финансовые процессы, следить за учетноаналитическими показателями, для принятия решений выявленных проблем. Например, разбить управленческую учетно-аналитическую систему по затратам, а уже затраты непосредственно по подразделениям, для дальнейшего облегчения мониторинга за этим. Главное чтобы в этой системе не потерялась 
взаимосвязь между ними. В таком случае, за каждой различный блок могло бы отвечать одно лицо, а в дальнейшем, допустим в конце каждого квартала, все данные собирались в единый управленческий отчет.

\section{Литература:}

1. Ульянова И.П., Попова Л.В.-Бухгалтерский учет: пособие для бухгалтера и менеджера.-М.:Бизнес-Информ, 1999.-С.140

2. Усатова Л.В.-Формирование учетно-аналитической системы на предприятия-Управленческий учет-2008-№9-С.17-25

3. Попова Л.В., Маслов Б.Г., Маслова И.А.-Основные принципы построения учетно-аналитической системы-Финансовый менеджмент-2008-№3-С.3467 